\title{
Description of Litomosoides ysoguazu n. sp. (Nematoda, Onchocercidae), a parasite of the tuft-toed rice rat Sooretamys angouya (Fischer) (Rodentia: Cricetidae), and a first record of $L$. esslingeri Bain, Petit \& Berteaux, 1989 in Paraguay
}

\author{
Juliana Notarnicola $\cdot$ Noé Ulises de la Sancha
}

Received: 12 December 2014/ Accepted: 15 March 2015

(C) Springer Science+Business Media Dordrecht 2015

\begin{abstract}
Paraguay is a small landlocked country whose mammalian fauna is among the least studied in South America, as well as their parasites. As a result of a study of the effects of habitat fragmentation on small mammal biodiversity in eastern Paraguay, we have collected some parasites of cricetid rodents. Herein, we describe a new species of Litomosoides Chandler, 1931 parasitising the body cavity of the tuft-toed rice rat Sooretamys angouya (Fischer) and Litomosoides esslingeri Bain, Petit \& Diagne, 1989 parasitising Oligoryzomys nigripes (Olfers), thus expanding its geographical distribution into Paraguay. Litomosoides ysoguazu n. sp. is characterised by the large size of the females (92.2-117.6 mm long) and by having buccal capsule with an anterior widening with rounded edges on the chitinous segment and a rounded widening at the base; male tail with a single pair of adcloacal papillae, three to five pairs of asymmetrical postcloacal papillae, and one or two unpaired papillae in the
\end{abstract}

J. Notarnicola $(\square)$

Centro de Estudios Parasitológicos y de Vectores CEPAVE - CCT La Plata-CONICET-UNLP, Boulevard 120 entre 61 y 62, 1900 La Plata, Buenos Aires, Argentina e-mail: julinota@yahoo.com.ar; julinota@cepave.edu.ar

N. U. de la Sancha

Department of Biological Sciences, Chicago State

University, 9501 S. King Drive, Chicago, IL 60628, USA

N. U. de la Sancha

Integrative Research Center, The Field Museum, $1400 \mathrm{~S}$.

Lake Shore Dr., Chicago, IL 60605, USA median ventral line; spicules corresponding to the "sigmodontis" species group; and microfilaria with a sheath stuck to the body and visible in the anterior extremity. We also describe a fourth-stage female larva. Oligoryzomys nigripes is a new host record of $L$. esslingeri; this enlarges the host record to eight species highlighting the low specificity of this species.

\section{Introduction}

Paraguay is a small landlocked country in the southcentral region of South America. The country includes five major ecoregions: the Atlantic Forest and Cerrado in eastern Paraguay, the Dry Chaco and Pantanal to the west and the Humid Chaco in the centre subdivided by the Rio Paraguay (Olson et al., 2001). The history of mammalogy is among the earliest of South America with mammalian records as early as 1550 to 1770 by the Jesuit missionaries of the region (López-González et al., 2014). However, the mammalian fauna of Paraguay is still among the least studied and understood in the continent (Myers et al., 2002; LópezGonzález et al., 2014) as indicated by the number of recent new and noteworthy records from this country (de la Sancha et al., 2007, 2009, 2011; D'Elía et al., 2008; de la Sancha \& D'Elía, 2015; among others) many of which reflect new recent collections.

The current knowledge of the parasite fauna of small mammals in Paraguay is even more scarce; there 
are few records of helmiths scattered both in space and time including nematodes of bats (Lent et al., 1946; Durette-Desset \& Vaucher, 1999), dasypodids (Lent \& Teixeira de Freitas, 1942; Masi Pallarés, 1970, 1990; Fujita et al., 1995) and marsupials (Masi Pallarés et al., 1976). For rodents there is only a single record of the oxyurid Passalurus ambiguus (Rudolphi, 1819) from Cavia aperea Erxleben, also reported from the lagomorph Sylvilagus sp. (Masi Pallarés et al., 1976).

As a result of a recent study of the effects of habitat fragmentation on the biodiversity of small mammals in eastern Paraguay (de la Sancha, 2010, 2014), we have collected parasite samples in several cricetid rodents. Herein, we describe a new species of Litomosoides Chandler, 1931 (Nematoda, Onchocercidae) parasitising the body cavity of the tuft-toed rice rat Sooretamys angouya (Fischer). Additionally, we include a noteworthy record of Litomosoides esslingeri Bain, Petit \& Berteaux, 1989 in Oligoryzomys nigripes (Olfers) thus expanding the data on host and geographical range of this species.

\section{Materials and methods}

The newly collected material is a product of sampling conducted within the largest remnants of Interior Atlantic Forest (IAF) left in eastern Paraguay, during December 2006 to March 2009. The IAF of eastern Paraguay is home to small mammal assemblages different from other portions of the coastal Brazilian Atlantic Forest (de la Sancha, 2014; de la Sancha et al., 2014).

The trapping consisted of 40 equally-sized grids in four reserves and included pitfall traps, snap traps, and Sherman live traps (de la Sancha, 2014). All mammalian samples trapped were collected as museum vouchers and were prepared as dry skin or specimens fixed in ethanol to be deposited at The Field Museum of Natural History, Chicago, Illinois, and the Natural Science Research Laboratory (NSRL), Texas Tech University, Lubbock, Texas, USA. Viscera were fixed in $10 \%$ formalin and stored in $70 \%$ ethanol. All applicable institutional, national and international guidelines for the care and use of animals were followed.

Filarial worms were cleared in lactophenol and the morphology examined using an Olympus BZ51 microscope. To examine the disposition of head papillae, a drawing was prepared from one female specimen in apical view. The lateral cuticular internal ridges were used to identify lateral fields and the Y-shaped section of the lumen of the oesophagus was used to identify the dorsal side. Cross sections of a female, posterior to the vulva, were cut with a razor blade and mounted in glycerin. Microfilariae were obtained from the uterus of one female. Illustrations were made with the aid of a drawing tube. All measurements are in micrometres unless otherwise indicated and are given as the range followed by the mean in parentheses. Type- and voucher specimens were deposited at the Colección de Helmintos Museo de la Plata (MLP-he), La Plata, Argentina and the Harold Manter Laboratory of Parasitology (HWML), Division of Parasitology, University of Nebraska State Museum, Lincoln, Nebraska, USA. Host species nomenclature and synonymy follow Weksler et al. (2006).

\section{Litomosoides ysoguazu n. sp.}

Type-host: Sooretamys angouya (Fischer) (Rodentia, Cricetidae); field number TK129367, adult male, collected on 11.xii.2007, deposited at The Field Museum of Natural History, Chicago, Illinois, USA, FMNH 226738.

Type-locality: San Rafael Managed Resource Reserve $\left(26^{\circ} 32^{\prime} 39^{\prime \prime} \mathrm{S}, 55^{\circ} 44^{\prime} 16^{\prime \prime} \mathrm{W}\right)$, Department of Itapúa, Paraguay.

Type-material: Holotype (male) (MLP-he 6820), allotype (female) (MLP-he 6821), paratypes: 5 males, 15 females, 8 anterior extremities, 5 posterior extremities (MLP-he 6822), and 1 fourth- stage female larva (MLP-he 6823).

Site in host: Abdominal cavity, between the intestinal mesentery and testis.

Prevalence and intensity: One of two hosts infected; 32 adult worms and 1 fourth-stage female larva.

Etymology: The species name means big worm: yso is a general name for parasitic worms in Guarani, one of Paraguay's official and indigenous languages and guazu means big in Guarani.

\section{Description (Figs. 1, 2)}

General. Females large, males c.4.6× shorter than females. Cephalic extremity rounded. In apical view, head papillae symmetrically arranged, 4 externo-labial papillae and 4 cephalic papillae, both circles of 


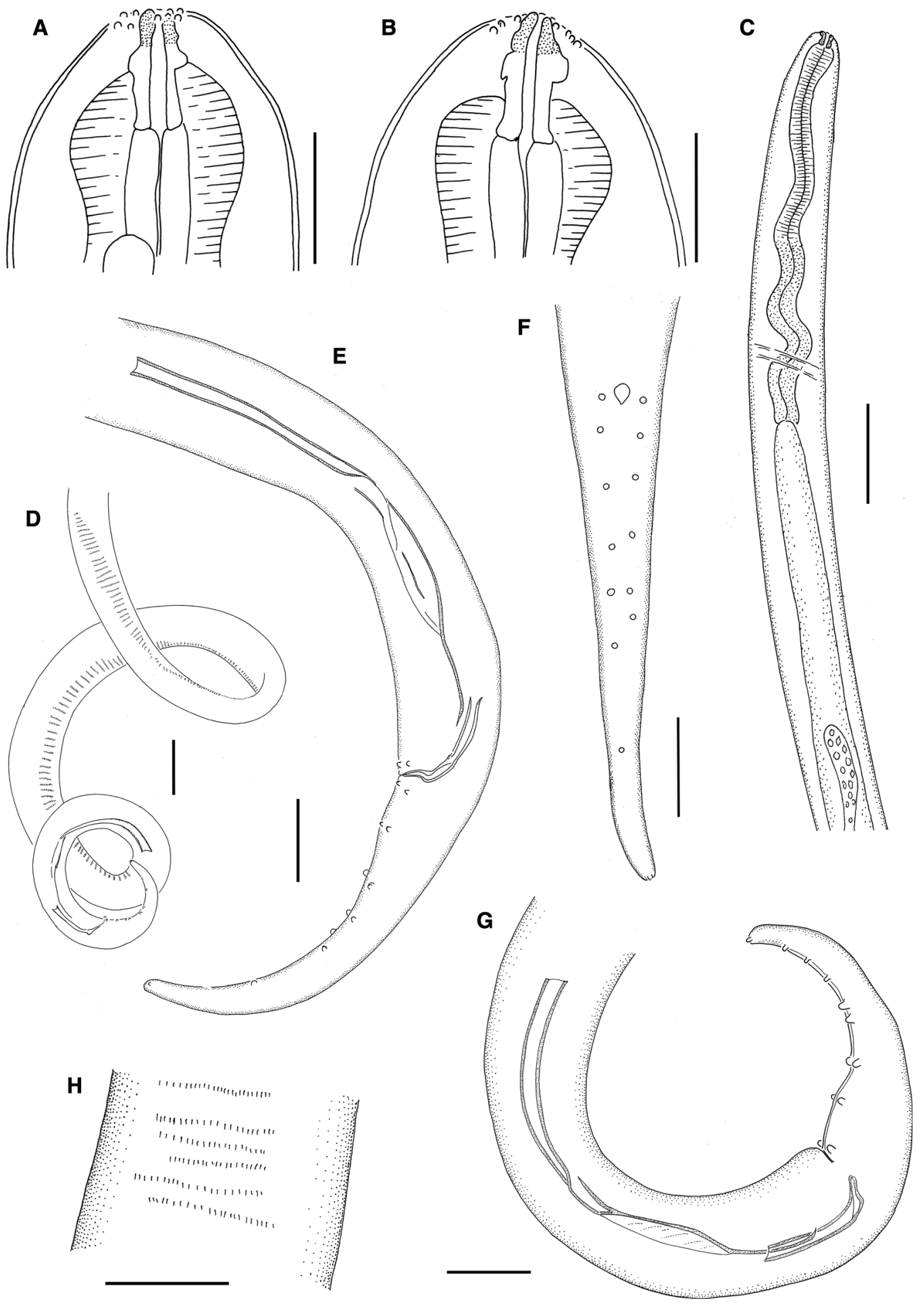

Fig. 1 Litomosoides ysoguazu n. sp. Male. A, Anterior extremity, lateral view; B, Anterior extremity, median view; C, Anterior region showing the tip of the testis; D, Posterior region; E, Paratype, tail in lateral view; F, Paratype, tail in ventral view; G, Holotype, tail with spicules, lateral view; H, Area rugosa at mid-length. Scale-bars: A, B, $20 \mu \mathrm{m} ; \mathrm{C}, \mathrm{D}, 100 \mu \mathrm{m} ; \mathrm{E}-\mathrm{H}, 50 \mu \mathrm{m}$ 


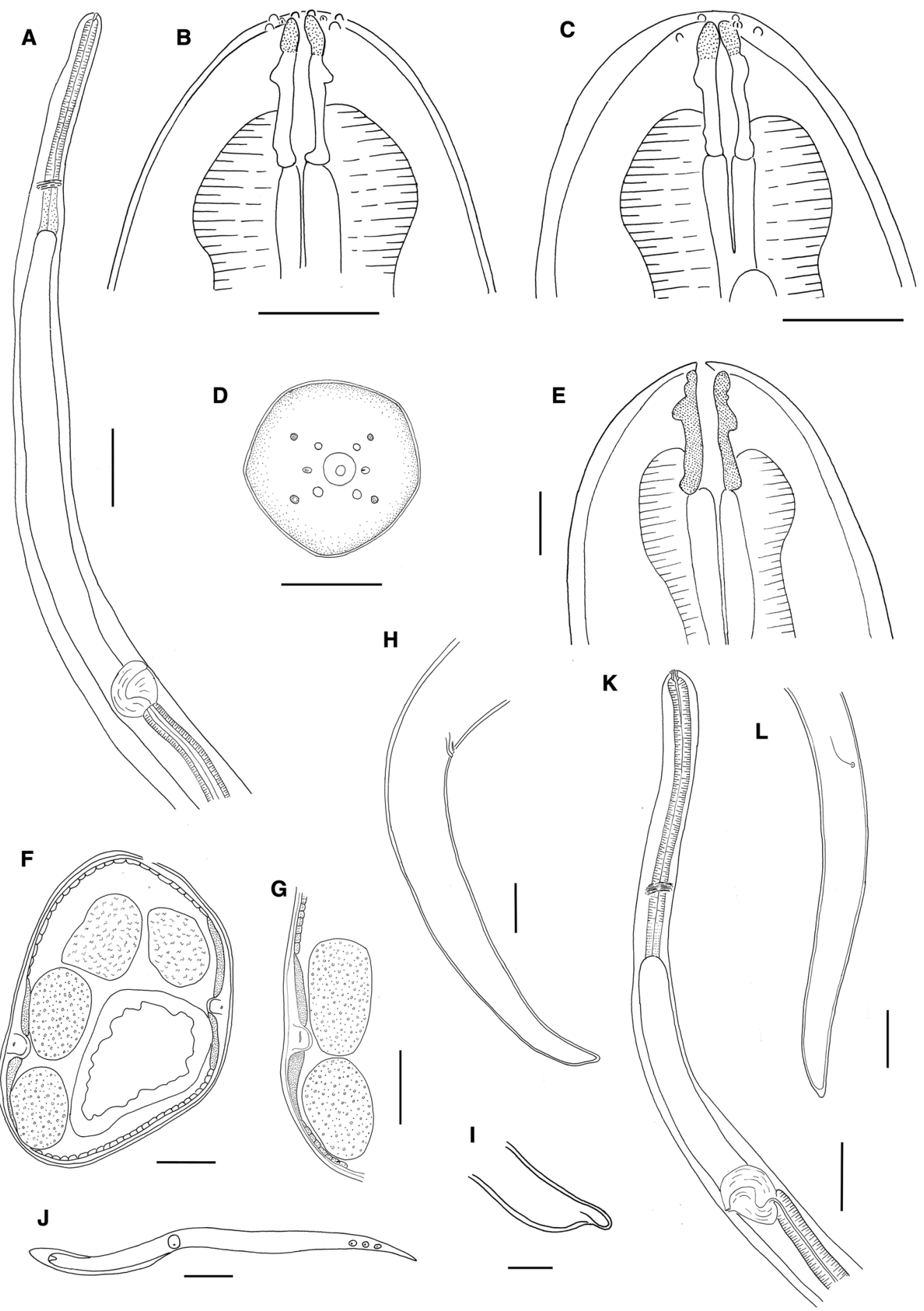

Fig. 2 Litomosoides ysoguazu n. sp. Female. A, Anterior region, lateral view; B, Anterior extremity, median view; C, Anterior extremity, lateral view; D, Anterior extremity, apical view; E, Fourth-stage female larva, anterior extremity; F, Transverse section posterior to the vulva; G, Detail of the lateral chord; H, Tail, lateral view; I, Tail extremity showing the amphids; J, Uterine microfilaria; $\mathrm{K}$, Anterior region of fourth-stage female larva, lateral view; L, Tail of fourth-stage female larva, lateral view. Scale-bars: A, $200 \mu \mathrm{m}$; B-D, $20 \mu \mathrm{m}$; E, I, J, $10 \mu \mathrm{m}$; F-H, L, $50 \mu \mathrm{m}$; K, $100 \mu \mathrm{m}$ 
papillae situated at dorso- and ventro-lateral lines (Fig. 2D); amphids lateral, not salient. Buccal capsule embedded in oesophagus, longer than broad, with transparent anterior segment followed by chitinous segment; chitinous segment possessing anterior widening with rounded edges and rounded widening at base (Figs. 1A, B, 2B, C); buccal cavity smooth, wider near base. Oesophageal apex dilated, with muscular anterior and slightly differentiated glandular posterior portion. Vulva posterior to oesophagointestinal junction. Tail attenuated.

Male [Based on 6 specimens]. Posterior region coiled, with 2 to 3 loops (Fig. 1D). Left spicule with handle shorter than blade (handle longer than blade in some specimens); blade constituted by membranous folded ala and terminal filament (Fig. 1E, G). Right spicule with poorly cuticularised heel (Fig. 1E, G). Tail attenuated, with single pair of adcloacal papillae, 3-5 pairs of asymmetrical postcloacal papillae, and 1 or 2 unpaired papillae in median ventral line (Fig. 1E, $\mathrm{G})$. Area rugosa consisting of transverse ridges made of small longitudinal crests, extends through coiled region (Fig. 1D, H).

Measurements: Holotype: Body length $23.5 \mathrm{~mm}$; width at mid-body 170 , at oesophago-intestinal junction 70, at anus 70; buccal capsule 20 long, external diameter 9; buccal cavity 3 wide; oesophagus 545 long; nerve-ring at 210 from anterior extremity; tail 212 long; left spicule 312 long, handle 150 long; right spicule 90 long; spicular ratio 1:3.4; area rugosa 1,300 long, extending from 675 to 1,975 from posterior extremity, ridges $c .4$ in height, spaced 6-12. Paratypes $(\mathrm{n}=5)$ : Body length 18.6-26.0 (22.8) mm; width at mid-body 132-165 (154); buccal capsule 20-23 (21) long, external diameter 6-10 (8); oesophagus 440-640 (544) long; nerve-ring at 200-350 (287) from anterior extremity; tail 200-275 (231) long; left spicule 253-335 (311) long, handle 121-170 (150) long; right spicule 80-110 (93) long; spicular ratio 1: 2.6-4.1 (1: $3.4)$; area rugosa $880-1,560(1,285)$ long, extending from $600-950$ (721) to $1,500-2,200(2,011)$ from posterior extremity.

Female [Based on 12 specimens.] Vulva far posterior to oesophago-intestinal junction. Vagina globular or sub-globular, ovejector muscular directed posteriad (Fig. 2A). Tail slender (Fig. 2H), anus difficult to observe. Phasmids small, divergent (Fig. 2I). In a transverse section posterior to the vulva, lateral hypodermal chords broad and flattened; internal cuticular ridges square-shaped (Fig. 2F, G).

Measurements: Allotype: Body length $100.5 \mathrm{~mm}$; width at mid-body 270 , at oesophago-intestinal junction 110, at level of vulva 180; buccal capsule 22 long, with external diameter 10 , buccal cavity 3 ; oesophagus 600 long; nerve-ring not visible; vulva at 1,950 from anterior end, located 1,300 from oesophago-intestinal junction; vagina sub-globular, $110 \times 100$; ovejector 1,200 long; tail 395 long. Paratypes $(n=9)$ : Body length $92.2-117.6(106.3) \mathrm{mm}$, width at mid-body 220-380 (284), at oesophago-intestinal junction 100-120 (112), at level of vulva 160-230 (197); buccal capsule 18-24 (22) long, with external diameter 10-12 (10); oesophagus 480-700 (598) long; nerve-ring at 120-530 (404) from anterior extremity; vulva $1,500-2,600(2,024)$ from anterior extremity, located 880-1,950 $(1,410)$ from oesophago-intestinal junction; tail $(\mathrm{n}=3)$ 550-560 (553) long.

Microfilaria. Body fusiform, slender, 67-77 (73) long, 4-5 (4.5) wide $(\mathrm{n}=3)$. Anterior extremity with small visible hook, tail attenuated, with nuclei at 12 from tip tail. Sheath present, stuck to body, visible at anterior extremity (Fig. 2J).

Fourth-stage female larva. Immature female short; body length $13.68 \mathrm{~mm}$; width at mid-body 110 , at oesophago-intestinal junction 50, at level of vulva 90 . Buccal capsule 19 long, with external diameter 10. Oesophagus muscular becoming slightly glandular near oesophago-intestinal junction, 430 long (Fig. 2K). Nerve-ring 330 from anterior extremity. Vulva close to anterior extremity compared with mature females, at 800 from anterior end and 380 from oesophago-intestinal junction; vagina globular, $85 \times 95$. Tail slender, 290 long (Fig. 2L).

Remarks

Litomosoides ysoguazu n. sp. belongs to the "sigmodontis" group of parasitic worms (Bain et al., 1989; Notarnicola et al., 2000; Bain et al., 2003) based on the morphological characteristics of both spicules. The left spicule has a handle shorter or as long as the blade, and the blade is divided into anterior membranous folded ala, with a terminal filament; the heel of right spicule is not heavily cuticularised. The "sigmodontis" group is 
comprised of 19 species found in rodents, marsupials and bats, with distinctive characters that make them different from the new species.

Litomosoides ysoguazu n. sp. can be differentiated from the three species parasitising bats, i.e. $L$. leonilavasquezae Caballero, 1939, L. fosteri Caballero, 1947 and L. teshi Esslinger, 1973, in having larger females, longer tail in both sexes, and a more posteriorly located vulva. Moreover, the new species possesses a robust buccal capsule, different from that of L. leonilavasquezae and L. fosteri, which is thinner, and from that of L. teshi, which possesses a dorsal thickening (Caballero, 1939, 1947; Esslinger, 1973).

Litomosoides ysoguazu n. sp. differs from L. barretti Muller, 1980, a parasite of the marsupial Micoureus demerarae (Thomas) (syn. Marmosa cinerea) from Brazil, in having females with a shorter oesophagus and a more posteriorly located vulva and males with a shorter right spicule (80-90 vs 100-120 $\mu \mathrm{m}$ ), and in having asymmetrically placed cloacal papillae instead of symmetrical (Muller, 1980).

In comparison with other species found in rodents, the new species differs from L. ctenomyos Brant \& Gardner, 1997 in having a shorter oesophagus, a longer tail in the male and a more attenuated tail in the female, and in the presence of cephalic papillae, absent in L. ctenomyos (Brant \& Gardner, 1997); from L. hoplomys Esslinger, 1973, a parasite of echimyd rodents from Colombia, in that L. ysoguazu n. sp. is a larger species, with an attenuated tail, and with a larger buccal capsule (females: 22 vs $19 \mu \mathrm{m}$; males: $21 v s$ $17 \mu \mathrm{m}$ ) with thicker walls (Esslinger, 1973). The new species differs from L. sigmodontis Chandler, 1931 in having a buccal capsule with a rounded thickening instead of irregular walls, and a shorter microfilaria (67-77 vs $84 \mu \mathrm{m})$ with a sheath visible at the anterior extremity instead of a long sheath visible at both extremities (Forrester \& Kinsella, 1973; Bain et al., 1989).

Body length of females of L. ysoguazu n. sp. (92-117 mm) is distinctly larger than that of females of L. patersoni (Mazza, 1928) (43 mm); L. oxymycteri Notarnicola, Bain \& Navone, 2000 (43.0-70.8 mm); $L$. anguyai Notarnicola, Bain \& Navone, 2002 (53.6-69.1 mm); L. nasuti Notarnicola \& Navone, 2009 (37.4-47.9 mm); L. navonae Notarnicola, 2005 (44.8-72.3 mm); L. taylori Guerrero \& Bain, 2011 (mean $54.3 \mathrm{~mm}$ ); and L. circularis (von Linstow, 1899) $(65 \mathrm{~mm})$. Moreover, the new species can be differentiated from L. patersoni in having a buccal capsule with a thickening instead of irregular walls, and by the slender microfilaria instead of a stout one (Notarnicola et al., 2010); from L. oxymycteri by the absence of a precloacal papilla (Notarnicola et al., 2000); from L. anguyai and L. nasuti in having no salient amphids and a complete set of head papillae (Notarnicola et al., 2002; Notarnicola \& Navone, 2009); from L. navonae in having a more posteriorly located vulva (mean 2,023 vs $1,359 \mu \mathrm{m}$ from the anterior extremity) and microfilaria with a sheath visible only at the anterior extremity (Notarnicola, 2005); from L. taylori by the presence of a thickening in the buccal capsule instead of irregular walls (Guerrero et al., 2011); and from L. circularis by a shorter right spicule (mean length $80-110$ vs $98-121 \mu \mathrm{m}$ ) and different spicular ratio (mean 3.5 vs 2.8) (Guerrero \& Bain, 2011).

Litomosoides ysoguazu n. sp. also differs from $L$. legerae Bain, Petit \& Berteaux, 1980, a parasite of Oxymycterus quaestor Thomas from Brazil, in having a shorter oesophagus in both sexes (males: 440-640 vs 720-800 $\mu \mathrm{m}$; females: 400-700 vs 1,040-1,240 $\mu \mathrm{m}$ ), a buccal capsule without irregular walls, and lateral hypodermic chord broad and flattened instead of narrow and tall (Bain et al., 1980); from L. galizai Bain, Petit \& Diagne, 1989 in possessing a buccal capsule with wider walls, and a different arrangement of the cloacal papillae (Bain et al., 1989); from $L$. chagasfilhoi Moraes Neto, Lanfredi \& De Sousa, 1997 by a longer tail in males (200-275 vs 143-187 $\mu \mathrm{m})$ and a buccal capsule without smooth walls (Moraes Neto et al., 1997; Notarnicola et al., 2000); and from $L$. esslingeri Bain, Petit \& Diagne, 1989 by the absence of a constricted tail tip in the female (Esslinger, 1973; Notarnicola et al., 2012). The new species differs from L. kohnae Bain, Petit \& Diagne, 1989 in having females with a tail curved ventrally instead of curved dorsally (Bain et al., 1989).

Finally, there is a group of Litomosoides spp., including five species parasitising bats, for which the males are unknown. The descriptions are based on females for three species and only on microfilaria for two species. These species can be separated from the new species as follows. Females of L. ysoguazu n. sp. are distinct from those of L. solarii Guerrero, Martin, Gardner \& Bain, 2002, a parasite of Trachops cirrhosus Spix in Peru, in having a more posteriorly located vulva $(2,024$ vs $910 \mu \mathrm{m}$ from anterior 
extremity) and also distant from the oesophagointestinal junction, and in having a tail without a sharpened point in the microfilaria as described in $L$. solarii (see Guerrero et al., 2002). Females of the new species are larger than those of L. artibei Esslinger, 1973, possess a thicker buccal capsule lacking anterior enlargements, and the vulva is distant from the oesophago-intestinal junction (Esslinger, 1973). The new species differs from $L$. chitwoodi Bain, Guerrero \& Rodriguez, 2003 in being larger (mean 106.3 vs $15 \mathrm{~mm}$ ) and in having a longer buccal capsule and a more posteriorly located vulva (Chitwood, 1938; Bain et al., 2003). The microfilariae of L. ysoguazu n. sp. are shorter than those described for $L$. colombiensis Esslinger, 1973, a parasite of Platyrrhinus dorsalis (Thomas) (recorded as Vampyrops dorsalis), and A. jamaicensis (Leach) from Colombia (67-77 vs $100-125 \mu \mathrm{m})$; and the caudal terminal nucleus does not reach the tail tip and is not markedly elongate as in L. colombiensis (see Esslinger, 1973). Finally, the microfilariae of L. ysoguazu n. sp. are longer than those of L. caliensis Esslinger, 1973 (67-77 vs 53-65 $\mu \mathrm{m}$ ) with an attenuated tail instead of rounded, and the terminal nucleus is not spheroid and does not reach the tail tip (see Esslinger, 1973).

\section{Litomosoides esslingeri Bain, Petit \& Diagne, 1989}

Host: Oligoryzomys nigripes (Olfers) (Rodentia, Cricetidae), field number TK129461, adult male, captured on 13.iii.2008, deposited at the Natural Science Research Laboratory (NSRL), Texas Tech University, Lubbock, Texas USA, TTU-M 118813.

Locality: Limoy Biological Reserve $\left(24^{\circ} 43^{\prime} 51^{\prime \prime} \mathrm{S}\right.$, $54^{\circ} 24^{\prime} 42^{\prime \prime} \mathrm{W}$ ) Alto Paraná Department, Paraguay.

Site in host: Abdominal cavity.

Prevalence and intensity: One of three hosts infected; 11 worms.

\section{Description}

General. Males one-third length of females. Cephalic extremity rounded; buccal capsule tubular, with irregular thickenings throughout and smooth buccal cavity; posterior part embedded in oesophagus. Cephalic papillae 4, situated at dorso- and ventrolateral lines; labial papillae 4, forming rectangle elongated in dorso-ventral plane. Oesophagus differentiated in muscular anterior portion and glandular posterior portion. Tail slender.

Male [Based on 3 specimens.] Body length 20.7-25.0 (23.3) mm; width at mid-body 120-140 (128). Buccal capsule 19-23 (21) long, external diameter 7-8 (8). Oesophagus 390-580 (503) long. Nerve-ring from anterior extremity 200-390 (270). Posterior region coiled. Tail 212-255 (227) long, with 4-6 pairs of cloacal papillae. Left spicule 280-330 (307) long, with handle 140-170 (153) long, shorter than blade; blade with anterior membranous alae and distal filament; right spicule 80-100 (90) long with heel not heavily cuticularised. Spicular ratio 1:3.3-3.5 (1:3.4). Area rugosa consisting of transverse ridges of small longitudinal crests.

Female [Based on 3 specimens.] Body length 60.0-82.5 (74.7) $\mathrm{mm}$; width at mid-body 192-270 (234), at oesophago-intestinal junction 60-82 (75), at level of vulva 80-190 (133). Buccal capsule 22-25 (24) long, with external diameter 9-10 (10). Oesophagus 500-680 (582) long. Nerve-ring 310-520 (403) from anterior extremity. Vulva posterior to oesophago-intestinal junction, at 1,400-1,750 $(1,550)$ from anterior extremity and 720-1,200 (953) from oesophago-intestinal junction. Vagina globular. Tail 600-870 (703) long, with constricted tip; width at anus 75-90 (82).

Microfilaria [Based on 5 intrauterine worms.] Body fusiform, slender, 60-70 (66) long, 3-6 (4) wide.

\section{Remarks}

Litomosoides esslingeri was originally described in Melanomys caliginosus Tomes (reported as Oryzomys caliginosus) from Colombia (Esslinger, 1973), and more recently reported from Oligoryzomys microtis Allen, Oligoryzomys sp., Eligmodontia puerulus (Philippi), Calomys lepidus (Thomas), Holochilus sciureus Wagner, Oecomys mamorae (Thomas) and Ctenomys opimus Wagner from Bolivia (Notarnicola et al., 2012) and from E. puerulus in northern Argentina (Notarnicola et al., 2012). This study provides the first record of L. esslingeri in Paraguay and a new host record.

Most of the diagnostic characters of the specimens collected in Paraguay match with those described by 
Esslinger (1973) and Notarnicola et al. (2012). The shape of the buccal capsule is uniform among all the specimens, as well as the shape of the spicules and the tail tip of the females. All these features are diagnostic traits for the species.

Notarnicola et al. (2012) recognised two different morphs in females of L. esslingeri: one includes females possessing a slender anterior extremity, with width $<100 \mu \mathrm{m}$ at the level of the oesophago-intestinal junction and $<180 \mu \mathrm{m}$ at the level of the vulva. The second, more robust morph includes females possessing a robust anterior extremity, with width $>120 \mu \mathrm{m}$ at the oesophago-intestinal junction and $>200 \mu \mathrm{m}$ at level of the vulva. Among our specimens, we also found females corresponding to both, the slender and robust morph.

\section{Discussion}

Helminth fauna of rodents in Paraguay is poorly studied. Herein, we report the first onchocercid parasitising the tuft-toed rice rat $S$. angouya and provide a new host (O. nigripes) and geographical (Paraguay) record for L. esslingeri.

The fourth-stage (J4) female larva of L. ysoguazu $\mathrm{n}$. sp. found in $S$. angouya adds information on the ontogenesis of Litomosoides spp. The oesophagus to body length ratio increases from $\mathrm{J} 4$ stage to the adult (mean 32 in $\mathrm{J} 4$ vs 178 in adults) as well as the vulva to body length ratio (mean 17 in $\mathrm{J} 4$ vs 52.5 in adults), similarly to the observations on $L$. brasiliensis, $L$. sigmodontis, L. legerae, and L. navonae (see Bain et al., 1980; Maréchal et al., 1996; Guerrero et al., 2002; Notarnicola, 2005). The female larva can be assigned to the new species because it shares the diagnostic features; however the body length was 7.7 times smaller than the length of adults.

The finding of L. esslingeri in a different cricetid species, not reported before, expands the data on host range to eight host species and demonstrates the low specificity of this filaria. Five of the 26 species of Litomosoides parasitising rodents and marsupials and three of the 15 species parasitising bats exhibit low specificity, e.g. L. brasiliensis is recorded in six host species, L. navonae in five host species, L. pardinasi in four host species, L. hoplomys, L. sigmodontis, $L$. chandleri and L. hamletti in two host species. It seems that the species of Litomosoides with low host specificity also show a wide geographical distribution whereas those species reported in a single host have a restricted geographical distribution. Additional studies are needed, as this will certainly increase the diversity of the genus and the known geographic distribution of its species.

Acknowledgements We thank all volunteers and workers who helped with field work with special thanks to Pastor E. Pérez, María Luisa Ortiz Willigs, Fredy Ramírez, Julio Torres, Lourdes Valdez, for assistance during different stages of fieldwork. We thank Bruce Patterson and William Stanley at the Field Museum, Heath Garner and Robert Baker at Texas Tech University, Andrea Wieler at the Colección de Zoología, Facultad de Ciencias Naturales y Exactas, and Scott L. Gardner at the Harold Manter Laboratory of Parasitology, University of Nebraska, for their help and access to collections. We thank the Secretaria del Ambiente for collection and exportation permits. Financial support to NDLS was provided by the Marshall Field Collection Fund of The Field Museum of Natural History in Chicago, the International Institute for Education (Fulbright Scholarship), several Lewis and Clark Exploration Fund grants, the Mary Rice Foundation, the TTU Association of Biologists mini-grant, a AT\&T/McNair Fellowship (TTU), assistantships from the Department of Biological Sciences (TTU), a Michelle Knapp Memorial Scholarship (TTU), and a Knox Jones Award (TTU). We thank María Cristina Estivariz from CEPAVE, for preparing the drawings. We are also grateful to Dr F. Moravec for his valuable comments on an earlier version of this manuscript. JN is a member of the CONICET.

\section{References}

Bain, O., Guerrero, R., Rodriguez, B., Babayan, S., \& Jovement, N. (2003). Examination of type material of two species of Litomosoides (Filarioidea: Onchocercidae), parasites from bats; Taxonomic consequences. Parasite, 10, 211-218.

Bain, O., Petit, G., \& Berteaux, S. (1980). Description de deux nouvelles Filaires du genre Litomosoides et de leurs stades infestants. Annales de Parasitologie Humaine et Comparée, 55, 225-267.

Bain, O., Petit, G., \& Diagne, M. (1989). Étude de quelques Litomosoides parasites de rongeurs: Conséquences taxonomiques. Annales de Parasitologie Humaine et Comparée, 64, 268-289.

Brant, S. V., \& Gardner, S. L. (1997). Two new species of Litomosoides (Nemata: Onchocercidae) from Ctenomys opimus (Rodentia: Ctenomyidae) on the altiplano of Bolivia. Journal of Parasitology, 83, 700-705.

Caballero, E. (1939). A new filariid worm from Mexican Bats. Transactions of the American Microscopical Society, 58, 456-458.

Caballero, E. (1947). Algunas filarias de mamíferos y de reptiles de las Repúblicas de Colombia y Panamá. Anales del Instituto de Biología de México, 18, 169-188.

Chitwood, B. G. (1938). Some nematodes from the caves of Yucatan. Carnegie Institution of Washington Publication, 491, 51-66. 
D’Elía, G., Moraf, I., Myers, P., \& Owen, R. D. (2008). New and noteworthy records of Rodentia (Erethizontidae, Sciuridae, and Cricetidae) from Paraguay. Zootaxa, 1784, 39-57.

de la Sancha, N. U. (2010). Effects of habitat fragmentation on non-volant small mammals of the Interior Atlantic Forest of eastern Paraguay. Dissertation, Texas Tech University, $199 \mathrm{pp}$.

de la Sancha, N. U. (2014). Patterns of small mammal diversity in fragments of subtropical Interior Atlantic Forest in eastern Paraguay. Mammalia, 78, 437-449.

de la Sancha, N.U., \& D'Elía, G. (2015). Additions to the Paraguayan mammal fauna: the first record of two marsupials (Didelphiomorphia, Didelphidae) with comments on the alpha taxonomy of Cryptonanus and Philander. Mammalia. doi:10.1515/mammalia-2013-0176.

de la Sancha, N., D’Elía, G., Netto, F., Perez, P., \& SalazarBravo, J. (2009). Discovery of Juliomys (Rodentia, Sigmodontinae) in Paraguay, a new genus of Sigmodontinae for the country's Atlantic Forest. Mammalia, 73, 162-167.

de la Sancha, N. U., D’Elía, G., Tribe, C. J., Perez, P. E., Valdez, L., \& Pine, R. H. (2011). Rhipidomys (Rodentia, Cricetidae) from Paraguay: noteworthy new records and identity of the Paraguayan species. Mammalia, 75, 269-276.

de la Sancha, N. U., Higgins, C. L., Presley, S. J., \& Strauss, R. E. (2014). Metacommunity structure in a highly fragmented forest: has deforestation in the Atlantic Forest altered historic biogeographic patterns? Diversity and Distributions, 20, 1058-1070.

de la Sancha, N. U., Solari, S., \& Owen, R. D. (2007). First records of Monodelphis kunsi Pine (Didelphimorphia, Didelphidae) from Paraguay, with an evaluation of its distribution. Mastozoología Neotropical, 14, 241-247.

Durette-Desset, M. C., \& Vaucher, C. (1999). Molostrongylus mbopi sp. n. (Nematoda, Trichostrongylina, Molineoidea), parasite de Molossops spp. (Chiroptera, Molossidae) au Paraguay. Revue Suisse de Zoologie, 106, 407-418.

Esslinger, J. H. (1973). The genus Litomosoides Chandler, 1931 (Filarioidea: Onchocercidae) in Colombian bats and rats. Journal of Parasitology, 59, 225-246.

Forrester, D. J., \& Kinsella, J. M. (1973). Comparative morphology and ecology of two species of Litomosoides (Nematoda: Filarioidea) of rodents in Florida, with a key to the species of Litomosoides Chandler, 1931. International Journal for Parasitology, 3, 255-263.

Fujita, O., Abe, N., Oku, Y., Sanabria, L., Inchaustti, A., \& Kamiya, M. (1995). Nematodes of Armadillos in Paraguay: A description of a new species Aspidodera esperanzae (Nematoda: Aspidoderidae). Journal of Parasitology, 81, 936-941.

Guerrero, R., \& Bain, O. (2011). Study of types species of "Filaria" (Nematoda) parasites of small mammals described by von Linstow and Molin. Parasite, 18, 151-161.

Guerrero, R., Bain, O., Martin, C., \& Barbuto, M. (2011). A new species of Litomosoides (Nematoda: Onchocercidae), parasite of Nectomys palmipes (Rodentia: Cricetidae: Sigmodontinae) from Venezuela: description, molecular evidence, Wolbachia pipientis screening. Folia Parasitologica, 58, 149-156.

Guerrero, R., Martin, C., Gardner, S. L., \& Bain, O. (2002). New and known species of Litomosoides (Nematoda:
Filarioidea): important adult and larval characters and taxonomic changes. Comparative Parasitology, 69, 177-195.

Lent, H., \& Teixeira de Freitas, J. F. (1942). Sobre Dipetalonema spiralis (Molin, 1860) (Nematoda, Filarioidea). Memórias do Instituto Oswaldo Cruz, 37, 383-389.

Lent, H., Teixeira de Freitas, J. F., \& Cavalcanti Proença, M. (1946). Algunos nemátodos de murciélagos coleccionados en el Paraguay. Revista Brasileira de Biología, 6, 485-497.

López-González, C., Myers, P., de la Sancha, N., D’Elía, G., \& Valdez, L. (2014). Historia de la Mastozoología en Paraguay. In: Ortega, J., Martínez, J. L. \& Tirira, D. G. (Eds) Historia de la mastozoología en Latinoamérica, las Guayanas y el Caribe. Quito and México DF: Editorial Murciélago Blanco, pp. 345-358.

Maréchal, P., Le Goff, L., Petit, G., Diagne, M., Taylor, D. W., \& Bain, O. (1996). The fate of the filaria Litomosoides sigmodontis in susceptible and naturally resistant mice. Parasite, 3, 25-31.

Masi Pallarés, R. (1970). Contribución a filarídeos observados en el Paraguay, la Dipetalonema anticlava (Molin, 1858). Revista Paraguaya de Microbiología, 5, 27-34.

Masi Pallarés, R. (1990). Nematodes de los vertebrados de Paraguay y otros parásitos del Nuevo Mundo. Asunción, Paraguay: Instituto de Investigaciones en Ciencias de la Salud and Universidad Nacional de Asunción, 689 pp.

Masi Pallarés, R., Benítez Usher, C., \& Maciel, S. (1976). Lista de helmintos del Paraguay. Revista Paraguaya de Microbiología, 11, 43-59.

Moraes Neto, A. H. A., Lanfredi, R. M., \& de Souza, W. (1997). Litomosoides chagasfilhoi sp. nov. (Nematoda: Filarioidea) parasitizing the abdominal cavity of Akodon cursor (Winge, 1887) (Rodentia: Muridae) from Brasil. Parasitology Research, 83, 137-143.

Muller, R. (1980). Litomosoides barretti n. sp. from the ashy opossum in Brazil (Nematoda: Filarioidea). Revista Brasileira de Biología, 40, 81-83.

Myers, P., Taber, A., \& Gamarra de Fox, I. (2002). Mamíferos de Paraguay. In: Ceballos, G. \& Simonetti, J. A. (Eds), Diversidad y Conservación de los Mamíferos Neotropicales. Mexico, DF: CONABIO, pp. 453-502.

Notarnicola, J. (2005). Description of adult and fourth-stage larva of Litomosoides navonae $\mathrm{n}$. sp. (Nematoda: Onchocercidae), a parasite of five species of sigmodontine rodents from northeastern Argentina. Systematic Parasitology, 62, 171-183.

Notarnicola, J., Bain, O., \& Navone, G. T. (2000). Two new species of Litomosoides (Nematoda: Filarioidea) in sigmodontines (Rodentia: Muridae) from Rio de La Plata marshland, Argentina. Journal of Parasitology, 86, 1318-1325.

Notarnicola, J., Bain, O., \& Navone, G. T. (2002). Litomosoides anguyai n. sp. (Nematoda: Onchocercidae) from Oxymycterus misionalis (Rodentia: Muridae) in the rain forest of Misiones. Argentina. Systematic Parasitology, 52, 129-135.

Notarnicola, J., Digiani, M. C., \& López, P. M. (2010). Redescription of the nematodes Litomosoides patersoni (Mazza, 1928) (Onchocercidae) and Stilestrongylus stilesi Freitas, Lent and Almeida, 1937 (Heligmonellidae) 
parasites of Holochilus chacarius (Rodentia, Cricetidae) from Salta, Argentina. Journal of Parasitology, 96, 993-1001.

Notarnicola, J., Jiménez Ruiz, F. A., \& Gardner, S. L. (2012). A new species of Molinema (Nematoda: Onchocercidae) in Bolivian rodents and emended description of Litomosoides esslingeri Bain, Petit, and Diagne, 1989. Journal of Parasitology, 98, 1200-1208.

Notarnicola, J., \& Navone, G. T. (2009). A new species of Litomosoides Chandler, 1931 (Nematoda: Filarioidea) from the long-nosed hocicudo Oxymycterus nasutus Waterhouse (Rodentia: Cricetidae) in Uruguay. Systematic Parasitology, 73, 87-94.

Olson, D. M., Dinerstein, E., Wikramanayake, E. D., Burgess, N. D., Powell, G. V. N., et al. (2001). Terrestrial Ecoregions of the World: A new map of life on earth. Bioscience, 51, 933-938.

Weksler, M., Percequillo, A., \& Voss, R. (2006). Ten new genera of Oryzomyine rodents (Cricetidae: Sigmodontinae). American Museum Novitates, 3537, 1-29. 